\title{
Emergent Ecosystem for Radical Innovation: Entrepreneurial Probing at Formula E
}

\author{
Sirkka L. Jarvenpaa \\ McCombs School of Business, \\ University of Texas at Austin, USA \\ sirkka.jarvenpaa@mccombs.utexas.edu
}

\author{
Willem Standaert \\ Vlerick Business School \& \\ Ghent University, Belgium \\ willem.standaert@vlerick.com
}

\begin{abstract}
Entrepreneurial action is increasingly associated with innovation ecosystems because no firm alone can render the complex and interdependent services demanded in markets. Moreover, entrepreneurial firms are increasingly instigators of innovation ecosystems, rather than merely participants. However, particularly in the pursuit of radical innovation, a question arises as to how an entrepreneurial firm begins to form and shape the landscape for an emergent ecosystem. In this paper, we examine the innovation activities of Formula $E$, a new venture at the hub of an emerging ecosystem, aiming to transform motorsports for digital-native fans. Digital technologies are providing nearly boundless possibilities but represent uncertain opportunities in terms of their ability to engage young fans, who previously have shown little interest in motorsports. We identify probing as a way to use initiatives to provoke engagement and generate openended dialog and discussion. Entrepreneurial probing helps to expand the innovation landscape in search of heterogeneous need-solution pairs.
\end{abstract}

\section{Introduction}

Digitization has rendered entrepreneurial action complex and collaborative [1]. Entrepreneurial action refers to organizing and operating activities of a business venture as it takes risks in discovering, evaluating, and exploiting opportunities [2]. No entrepreneurial firm can control all the resources and their integration, particularly when innovation is targeted at digital services and experiences [3]. Innovation requires both dynamic relationships with diverse partners across industry boundaries and knowledge collaboration in user communities [4]. Consequently, entrepreneurial action is less confined to the cognitive and emotional capacities of a single entrepreneur, an intact team of entrepreneurs, or even a stable set of alliance relationships. To organize entrepreneurial action in digital service ecosystems, collaboration needs to transcend producer-consumer divides [3]. In digital service innovation, users become critical business partners as co-creators of these experiences.

Ecosystems are constellations that bring together diverse partners across different industries to "coevolve capabilities around a new innovation: They work cooperatively and competitively to support new products, satisfy customer needs, and eventually incorporate the next round of innovations" [5, p. 76]. Innovation ecosystems are recognized as an important context for entrepreneurial action that seeks to leverage digital technologies [6], [7]. However, the prevailing focus in the literature has been on entrepreneurial firms as participants and complementors and not as anchors instigating, leading, and orchestrating ecosystems [8][10].

How does an entrepreneurial firm grow an ecosystem for radical innovation? Radical innovation implies radical departures from existing practices, business models, market categories, or customer groups. To pursue such radical opportunities in an ecosystem requires an entrepreneurial firm to take significant risks and venture into landscapes where "you don't know what you don't know." The entrepreneurial firm has to constantly play, poke, and shape the contours (limits) of the landscape to attract new partners and user communities.

Von Hippel and von Krogh [11] argue that in highly uncertain environments, informal and broad parallel external searches of need-solution pairs can be more cost effective than the traditional practice of engaging first in problem formulation in advance of "solving" the problem. But the broad search assumes a rich landscape with lots of different locations for opportunities. The entrepreneurial literature acknowledges that opportunities are endogenously created by the enactment of entrepreneurs [12]. Entrepreneurial action can target social trends and changes in user profiles and behaviors [1]. The 
equifinality of digital technologies also suggests that a range of technologies can be competing to meet the user or customer need [13]. All this speaks to the potential for an entrepreneurial firm to cultivate a rich landscape for an ecosystem where a heterogeneous set of opportunities can be present.

We examined the early-stage entrepreneurial ecosystem of a new venture, Formula $\mathrm{E}$ (FE), in the sports entertainment industry. The ecosystem comprised of diverse partner firms, along with fluid and diverse user communities. The venture sought to become the hub of an ecosystem that would disrupt the motorsports world by leveraging digital technology, transforming how the sport is experienced, played, and defined. FE was targeting the next generation of fans, millennials, who had previously shown little interest in motorsports. While an abundance of digital technologies was unceasingly emerging, which digital technologies would be appropriate in this digital transformation was uncertain.

FE, in close collaboration with ecosystem partners, launched a diverse array of digital experiences and applications enabled by mobile, social, virtual reality, gaming, crowdsourcing, and connected and autonomous car technologies. With these initiatives, which were co-created with fans and business partners, the venture began to poke and shape the limits of the innovation landscape: (1) how sports fans would want to engage in digital experiences; (2) how sports would be played/performed; and (3) how new sport competitions and categories could be invented. The initiatives became hotspots for the meaning-making of innovative possibilities, but also generated tensions and different perspectives among different actors in the ecosystem. In the process, both the uncertainties and the landscape of opportunities for the ecosystem increased.

Our contribution is positioned as complementing existing literature on ecosystems, radical innovation, and entrepreneurial opportunity creation. We examine radical initiatives of an entrepreneurial firm with limited resources and discover the notion of probing as a way to expand the landscape for its ecosystem. Probing is both deliberate and emergent: it is deliberate in terms of provocation; it is emergent in terms of engaging in continuous discussions.

Similar to what is written about cultural probes in the human-computer interaction literature, the initiatives at FE probed surprises and challenged "thoughts and assumptions about people and situations being designed for" [14, p. 57]. While cultural probes focus on demand-side reactions [14], the initiatives we analyzed were poking on both the demand and supply side under high levels of uncertainty in search of needsolution pairs [11]. We introduce the term "entrepreneurial probing" because it is used to expand the landscape for innovation opportunities. New opportunities attract new business partners and user communities to join and form new configurations in co-creating experiences.

Next, we review concepts of ecosystems, radical innovation, and entrepreneurial opportunity creation. We then report on our empirical study. We conclude the paper with a discussion of probing as a way to grow and shape the innovation landscape for the entrepreneurial ecosystem.

\section{Theoretical Background}

We briefly review literature on ecosystems, radical innovation, and entrepreneurial opportunity creation.

\subsection{Ecosystems}

Building on Moore [5], Nambisan and Baron [6] defined an innovation ecosystem as a "loosely interconnected network of companies and other entities that coevolve capabilities around a shared set of technologies, knowledge, or skills, and work cooperatively and competitively to develop new products and services" (p. 1071). Ecosystems are not necessarily tied to a coherent and bounded architecture comprising interoperable technologies. Instead, ecosystems consist of a hub firm, partners, user communities, and other stakeholders that offer complementary innovations across different and even competing platforms. In ecosystems, the partnering firms have their own logics and innovation trajectories. The various actors gain innovation leverage that comes from learning about each other's activities and from sharing resources, including mindshare in terms of a common purpose [8]. Innovation ecosystems facilitate the creation of new industries and radical goods and services, and they potentially reduce the cost and increase the profitability of innovation [8], [9].

Research on ecosystems has predominantly focused on large and incumbent organizations as orchestrators or hub firms. The focus has been on leadership, control of critical resources, and value appropriation within a technology-based hub firm that has market power [8]. Adner [15] emphasized the need for tight control to manage interdependence and integration risks. Ecosystems can spawn much entrepreneurial activity by lowering the costs and risks, because the central player provides incentives to its partners to "co-evolve, align their goals and activities, and further bond themselves to one another" [16, p. 220]. The literature limits the role of entrepreneurial firms as partners, or complementors, in ecosystems [8]-[10], rather than as anchors instigating, leading, and orchestrating 
ecosystems. New ventures are encouraged to connect to ecosystems but not to create the ecosystems themselves [6].

Hence, the emergence of entrepreneurial ecosystems might be argued by some researchers to be conceptually and theoretically anomalous. First, ecosystems are seen as networks that are "the product of a long and evolutionary process that defines relationships among industry players" [16, p. 219]. The entrepreneurial firm's need for a short-term focus for survival runs counter to this long and evolutionary perspective of an ecosystem. Second, building an ecosystem requires flexibility and adaptability, but new ventures are known to be prone to rigidity and overconfidence [16]. Third, to avoid a well-established and resourced incumbent from entering and crowding out the innovation space, the venture needs to target risky and bold emergent innovation areas that are too far from the interests and capabilities of incumbents. Zahra and Nambisan [16] argued that for an entrepreneurial firm in an ecosystem pursuing radical opportunities is a must, even in the absence of market potential.

\subsection{Radical Innovation}

Recently, Lyytinen Yoo, and Boland [17] proposed a new organizing form for radical digital innovation, created by the distributed, fluid, editable, and configurable nature of digital technologies. The new form is an anarchic innovation network. Such networks consist of "a heterogeneous pool of actors and tools... [but] in the absence of hierarchical control and presence of high levels of knowledge heterogeneity" [17, p. 59]. In an anarchic network, control is distributed throughout the network as each autonomous entity (e.g., firm, community, partnership) pursues innovations that make sense for its innovation trajectories. A plethora of different innovations is produced-so-called wakes [18]. Each wake comprises its own technologies, practices, structures, and strategies. As these wakes interact, much disruption and overlap occur, but in addition, trading zones emerge where intercalating innovations give rise to the next set of wakes. The trading zones promote "negotiations, collaboration, and learning through mutual perspective making and taking" [18, p. 635].

Similar to wakes, Majchrzak et al. argued that a "quantum leap in insight" [19, p. 14] can occur when participants in the innovation process maintain their own distinctive work processes, but structures and processes are also put in place that "facilitate the confluence of participatory 'spurts' of innovation."

One key aspect of anarchic networks described by Lyytinen et al [17] is that they are not designed ex ante because the knowledge resources needed for innovation are not known a priori. Rather, anarchic networks emerge through interactions among various heterogeneous partnerships and collaboration opportunities. But neither Lyytinen et al. [17] nor Majchrzak et al. [19] address the challenges of an entrepreneurial firm in emerging a radical innovation network. How to formulate a rich landscape of opportunities so that a search for heterogeneous needsolution pairs can take place?

\subsection{Entrepreneurial Opportunities}

Entrepreneurship is defined as "the pursuit of opportunity beyond the resources you currently control" [20, p. 1], and opportunity is a "future situation which is deemed desirable and feasible" [21, p. 23]. While traditionally it was assumed that "there is no entrepreneurial opportunity without customer demand" [22, p. 1494], now such demand is so fragmented, fluid, and rapidly changing, that opportunities are created by entrepreneurs embedding themselves in real-time customer "conversations" [23]. But such conversations assume that there is some certainty in terms of relevant user communities. In the early stage ecosystem aiming for markets and service categories that do not yet exist, there is high uncertainty about customers and technologies for interaction and engagement. There are also uncertainties regarding potential business partners and how to mobilize their resources and enact opportunities for innovation wakes that would then bring about additional business partners to the network to experiment, play, and engage in other forms of exploration [18].

Some form of probing might provoke diverse reactions and encourage interactions and experiences that transcend current limits of the innovation landscape in an entrepreneurial ecosystem. In human interaction design, the concept of probing is deployed to open hidden and invisible territories and embrace uncertainty and poetic possibilities. Probing (or probes) is an engagement strategy that involves provocation, ambiguity, absurdity, opacity, inspiration, and pleasure [24], [25]. Probes involve a provocative act or artifact that is novel and rich. Probes deliberately challenge taken-for-granted assumptions, norms, and rational thought. The provocations instigate inspirational and emotional responses, creating a dialogue and a common language with users that result in "a kind of intimate distance that can be a fruitful standpoint for new design ideas" [26, p. 55]. Such inspirational data from probing is not expected to be analyzed but rather stimulate possibilities. While the provocation is intentional, the inspirational responses are 
indeterminant. As McDougall and Fels [14, p. 57] wrote "Probes are instruments that are metaphorically based on the concept of sending probes into the complete unknown of outerspace and then waiting for data that may or may not come back to try to make sense of it without assuming what it might be or where it comes from." Probing does not assume that the target user group is known and it does not test any hypotheses. Hence, it is different from many prevailing methods such as the minimum viable product [27].

The earliest form of probing was cultural probing. This is a discovery process to be used when users might not know their own needs or desires, and through which designers might pose their own expectancies and users are faced with novel, aesthetically rich artifacts [25], [28]. Gaver et al. [25] were adamant that probes are not analyzed as rational processes to filter out the subjectivity in the responses on which the probe is seeking to shed insight. Probing is a rather broad concept with many different variations [2], [24]. As probing relies on eccentric observations, it has remained elusive and poorly understood, outside the design fields.

To summarize, while the reviewed literature provides insight into ecosystems, radical innovation, and pursuit of entrepreneurial opportunities, we note a lack of knowledge about what might happen at the intersection of these areas. The literature on ecosystems has considered early ventures to be participants - not hubs of ecosystems. While the research on radical innovation adds to the knowledge on how different firms in anarchic networks autonomously pursue their digital innovation trajectories, it offers little elaboration on how an entrepreneurial firm entices these autonomous firms to join the ecosystem in the face of high uncertainty. The literature on entrepreneurial opportunity formation has focused on the articulation of market and customer aspirations and technology opportunities through social information, but less when markets, customers, and technologies are all indeterminant. For a newly formed entrepreneurial firm, the question follows: How does an entrepreneurial firm grow an ecosystem for radical innovation?

In addressing this question, we structure our analysis around digital initiatives that may enact as open-ended probes. These initiatives involve digital technologies that are associated with equifinality [13]: The same user need can be addressed via different technological means. In other words, because of the decoupling of information from technologies (i.e., resource liquefaction) [3], digital objects can be rendered in nearly an infinite number of ways. For example, a sports fan can have a virtual, immersive, and personalized experience via mobile video, $360^{\circ}$ video, augmented reality, or virtual reality.

Initiatives serving as probes can expand the landscape by generating new cognitive and social translations [17]. Cognitive dynamics "form a generative dance of knowledge identification, sourcing, creation, dissemination and validation" [17, p. 56]. Social translation involves redefining and negotiating the meaning of innovations, identities, and roles through interactions, which leads to sense-making and sense-giving within a web of relationships. The more radical the innovation, "the more dynamic the ebb and flow of knowledge and perspectives" [17, p. 56] and the more likely are tensions among different actors. These tensions can expand the space of the ecosystem for new opportunities as different social interactions are contextualized and threaded [23].

\section{Method}

Our research was inspired by our reading of a Financial Times article on Formula E (FE). ${ }^{1}$ FE was the first international fully-electric racing series, sanctioned by the Fédération Internationale de l'Automobile (FIA). The organization behind the new championship was Formula E Group, which had obtained its 25-year license from the FIA in 2012. Although the FIA acted as a governing body in terms of safety and fair competition for several motorsports, Formula E acted autonomously in pursuing innovations and building its ecosystem.

After observing FE's activities for a couple of months, we learned that it engaged in rampant exploration of the innovation space, evidenced by having launched a variety of digital initiatives and building a remarkable ecosystem in the process. After only two years, the ecosystem included established firms and tech startups in the automotive, entertainment, finance, luxury, and logistics industries, as well as vibrant online user communities, such as those on Reddit and Facebook. The innovation network around FE was ever-expanding, with new (team) sponsors or partnerships announced almost on a weekly basis, rendering a revelatory case study.

Because of our "general wonderment" of what the venture had accomplished in a short amount of time, we felt the need to delve more deeply into FE's ecosystem and activities by conducting a case study. A case study approach is appropriate for examining the emergence of a new phenomenon, when the context is complex and dynamic and the research question is of the type, "why" or "how" [29], [30].

\footnotetext{
${ }^{1}$ Mitchell, Tom, "China's Formula E electric car circuit plugs into desire for clean air," Financial Times, December $8^{\text {th }} 2015$.
} 


\subsection{Case context}

For the FIA, FE provided an opportunity to promote clean energy and sustainability, issues for which FIA's flagship championship, Formula 1, was often criticized. FE had set itself to challenge the notions not only of pollution, but also of elitism and sexism perceptions in motorsports. After two years of developing, testing, and demonstrating the electric single-seater, as well as engaging teams, drivers, and sponsors, the inaugural season was kicked off in Beijing in September 2014. Although some aspects of FE were the same as in other racing series (e.g., two drivers per team), the championship was unique in several ways: The cars were fully electric; races, referred to as ePrixs, were held in different city centers around the globe instead of on dedicated race tracks, which was possible because of the lack of air pollution and low noise levels produced; and qualifying and the race itself were held on a single day, instead of multiple days.

Moreover, FE aimed to transform prototypical industrial-era motorsports for baby boomers into a digital-era sports category for millennials, who had shown little interest in motorsports so far. Millennials represented a highly diverse and disparate group that had fickle values and interests. Not only were they generationally, culturally, and knowledge-wise distant from the conventional notions of motorsports fans, but they also showed little interest in driving or owning a car. Hence, FE faced significant uncertainty about who potential fans for the new sports series could be. Yet, positioned as the next-generation motorsports for the digitally literate millennials, FE sought to attract attention by launching different digital initiatives to engage potential fans in transforming how motorsports was experienced, performed, and defined. In particular, during the first two years of race operations, FE had launched various initiatives, leveraging digital technology such as social media, gaming, virtual reality, and artificial intelligence.

\subsection{Data collection and analysis}

We collected data on FE, its ecosystem, and its digital initiatives from several sources. Gathering multiple sources is generally considered to be important in case study research because doing so can highlight different perspectives, adding to the complete picture of the case [30]. We initially gathered publicly available data from FE, such as their press releases and news and social media channels. We furthermore examined FE's financial statements and annual reports. In addition, we collected data from third-party sources, such as news websites and fan forums and communities (on Reddit and Facebook). In addition, we analyzed interviews with key people at FE (e.g., CEO Alejandro Agag and CMO Ali Russell) that appeared in news journals, in magazines, and on websites. Furthermore, we attended the Long Beach, CA (US) and London (UK) ePrixs in person, for a firsthand experience of all of the on- and side-track activities. Also, 16 fans were briefly interviewed at Long Beach and 10 at London about how they experienced the event, what digital channels they used during and in-between races, and how they felt about the fan engagement initiatives at FE. One of the authors served as the administrator of a local Facebook FE fan site. Finally, we conducted an interview with Tom Halls, Head of Digital at FE, about the various digital initiatives and the role of feedback from social channels.

We organized and analyzed this data based on the timeline (i.e., origin, planning phase, season 1, season 2 , future plans), as well as based on different structures and issues (e.g., key actors, regulation changes, partners, fan engagement initiatives, support series, sponsors, sustainability). Several distinct themes emerged from the analysis: digital entrepreneurship, innovation ecosystems, hybridity (blend of physical and digital worlds), process virtualization, fan entertainment and engagement, and environmental issues. As a next step, we developed a descriptive teaching case on FE, touching on all of these themes, yet focusing primarily on FE's digital fan engagement initiatives on and off the track.

At the starting point, we had no idea that probing would emerge as a practice that helped to explain a pattern of behavior across the initiatives. However, as we triangulated our observations with the service ecosystem and radical innovation literatures, some anomalies appeared to surface. To understand what was happening at FE, we entered an iterative process of data collection, analysis, and literature study. We used several structures to arrange the information, such as addressing the questions why, how, and for whom is FE launching these initiatives, and examining the inputs, processes, and outputs of the digital initiatives. We performed our analysis without predispositions but with an open mind for unexpected themes or patterns, allowing an engagement strategy, probing, to emerge.

\section{Findings}

Because of ample knowledge heterogeneity and the autonomy of action by various actors, FE's ecosystem appears to resemble an anarchic network form. The case is notable in the sense that we see an innovation ecosystem at an early stage, when anarchic forms might be particularly common to create radical 
innovations. The ecosystem is not preplanned but rather is evolving, as is the vision of what a nextgeneration motor sport could be. In this section, we present a number of initiatives $\mathrm{FE}$ had launched to simultaneously demarcate and expand the innovation space in terms of (1) engaging sports fans in digital experiences, (2) redefining fan engagement in sports performance, and (3) inventing new sports competitions and categories. We analyze the social interactions these initiatives engendered (on Facebook, Twitter, and Reddit) and the sequence of managerial decisions at FE that further pushed and poked at the limits of the innovation landscape.

\subsection{Engaging sports fans in digital experiences}

FE was interested in the exploration of digital user behavior that would allow for an experience of motorsports in a fan-centric, immersive wayespecially for those fans who could not attend the race physically. Hence, FE was pioneering $360^{\circ}$ videos and virtual reality in the sports world, which virtually put the fan in the driver seat. FE management commented: " $99 \%$ of the fans cannot attend the race, which is conventionally thought of as the best fan experience. We believe, however, that remote digitally-enabled immersive engagement can go beyond the real-life fan experience."

In particular, via the mobile app and in partnership with 360 Racing, FE enabled fans to choose among $360^{\circ}$ video live streams from onboard four cars, as well as from fixed positions, during the race. At the same time, FE was developing virtual reality re-creations of the races in collaboration with Virtually Live. More specifically, computer-generated images of the tracks and the cars were combined with live data about car position, speed, movement, etc. As a result, fans could choose any position around the track, as well as any driver's car, and see what is happening as the race is taking place. These experiences were available live, but also were offered for download, for deferred consumption. Other $360^{\circ}$ videos, available on YouTube and Facebook, and virtual reality experiences, available on the Oculus, HTC Vive, and PlayStation Virtual Reality platforms, included a pit stop clip, as well as behind-the-scenes footage of the paddock and teams' garages.

The social interactions that ensued, uncovered how differentiated the community was. Some fans were enthusiastic about these initiatives, and their reactions confirmed FE's claim that it had potential to go beyond the real-life experience, as this fan quote illustrates: "It's cool to wander into garages and areas that are usually cordoned off to fans." Other fans identified unexpected uses of the footage, as one fan commented after attending the race in person: "When you are attending the race, you can easily miss out on some pivotal action. With these technologies, [you] can replay exciting and controversial moments, from whatever angle of your choosing." However, the equifinality of digital technology instigated conversations within the fan community, as this quote illustrates: "I could see the point of the 360 degree onboard videos, but having a computer-generated image version of the race seems utterly redundant, when you can just watch the real thing." Finally, some saw the experience that current technology offered as limited: "Motorsports is a highly sensory experience, it's not just about the sights and the noise, it also involves smelling and touching the cars. Moreover, this is a social event, yet these immersive technologies provide primarily private experiences."

These interactions provided FE management with new openings to further transform and augment the digital fan experience. Also, through direct interaction with the fan community on Twitter (see Figure 1), FE management (Tom Halls, Head of Digital at FE) found additional paths for innovation: "Fans are asking for access to the drivers' live audio streams. Obviously, this is very sensitive as team strategies are discussed there, yet this is the kind of disruption we embrace in this championship." FE sought to expand the digital fan experience even further, as management wondered whether fans might be able to interact in real-time with drivers during the race.

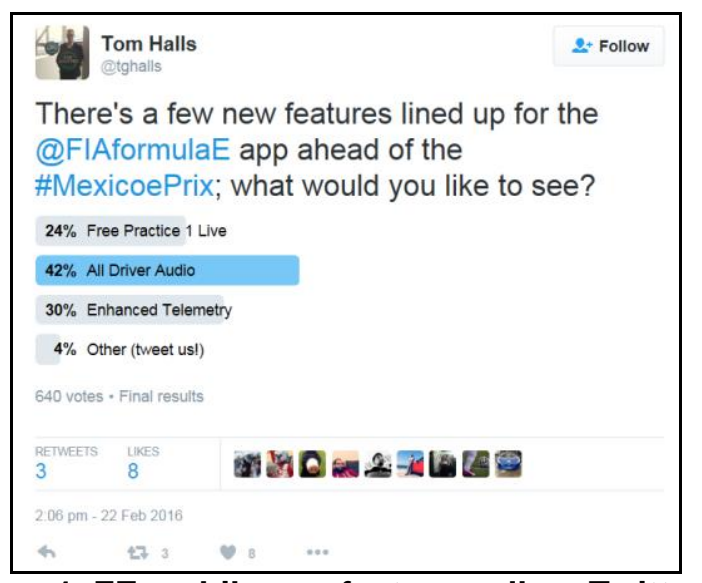

Figure 1. FE mobile app feature poll on Twitter

\subsection{Redefining fan engagement in sports performance}

FE was redefining how fans could be engaged in the performance aspect of motorsports. Through the FanBoost initiative, fans were enabled to affect the race outcome in an unprecedented way, directly influencing the performance of drivers through a 
crowdsourcing capability called FanBoost. In particular, when fans through crowdsourcing supported their favorite driver with their vote, the latter could get extra power during the race; the three drivers with the most votes were awarded the FanBoost. FE management commented: "We are merging social media and motorsport in unprecedented ways; this is truly gamifying the sport!"

Fans could vote via social media (Twitter, Instagram), using specific hashtags. However, fans could also cast their vote through less open mechanisms, such as FE's mobile application and website. In particular, fans were allowed one vote per mechanism per day. Moreover, FE displayed the ranking of FanBoost votes, but not the actual voting numbers for each driver.

For this initiative, tensions and divided perspectives among fans and drivers clearly emerged. On the one hand, FanBoost generated emotional and personal interactions between drivers and fans, as revealed in this fan quote: "I FanBoosted Bruno Senna on Instagram, and he said thank you for voting. I felt great because he used it to pass Prost in the race!" However, another fan commented: "FanBoost has nothing to do with sport, racing, or driving. It is a pathetic attempt to make motor racing more like a video game to draw in the moronic PS3 generation."

Moreover, what was trending among fans and drivers was the legitimacy of FanBoost, and the alleged use of bots that generate automated messages to artificially increase votes. As a result, the drivers had a love-hate relationship with FanBoost, as this driver quote after Season 2 illustrated: "I like FanBoost, and I think it is a really great feature to have in the championship. However, the voting system should change to just votes via social media, which makes the system very easy to monitor. What I like about sport is a fair way of competing. Cheating in any way, for instance by buying votes for FanBoost, is wrong. Formula $E$ is in discussions about how to improve it for next season, and they have all the support from the drivers as we want to keep it for Season 3 and beyond." (FE had already adapted the mechanisms between Seasons 1 and 2, such that the influence of it on performance decreased.)

By listening to social interactions, FE also was able to adapt other aspects of the mechanism. In particular, the voting window opened 12 days prior to each ePrix, at which point teams and drivers started reaching out to their fan base because they realized the fan support could help them win races. FE management commented: "We have to balance the stimulation of excitement prior to the race with the risk of oversaturation." Moreover, whereas in Season 1, voting ended before the start of the race, in Season 2,
FE allowed voting six minutes into the race. FE commented: "We learned that fans disliked the fact that if their favorite driver crashed in the first corner, they basically wasted their vote. So by extending voting six minutes into the race, we now see that if a crash happens, fans shift their vote."

Finally, what often happened was that local drivers - those coming from countries where the ePrix was held-gained momentum and won the FanBoost. FE learned that different voting mechanisms were used in different regions. As FanBoost became increasingly popular among fans, FE engaged Telescope, which supports real-time viewer voting for television shows, such as American Idol, to help in counting the votes, adding to the legitimacy perceptions of FanBoost.

\subsection{Inventing new sports competitions and categories}

FE also pushed the boundaries in terms of defining new sports competitions and categories. In fact, with the first, fully electric racing series, it had already authored a new category of sport. Moreover, FE started exploring eSports opportunities midway through Season 2, to stimulate the interest of potential fans who had never bought or even driven a real car but who might be familiar with racing from video games. It set up two "RaceOff Exhibition Events," at which fans could qualify for a virtual race with two professional FE drivers. After the event, FE gathered feedback from fans-for instance, through Twitter (see Figure 2). According to FE management: "The events were a big hit; based on this success and the positive buzz around it, we decided to launch additional initiatives in the gaming space."

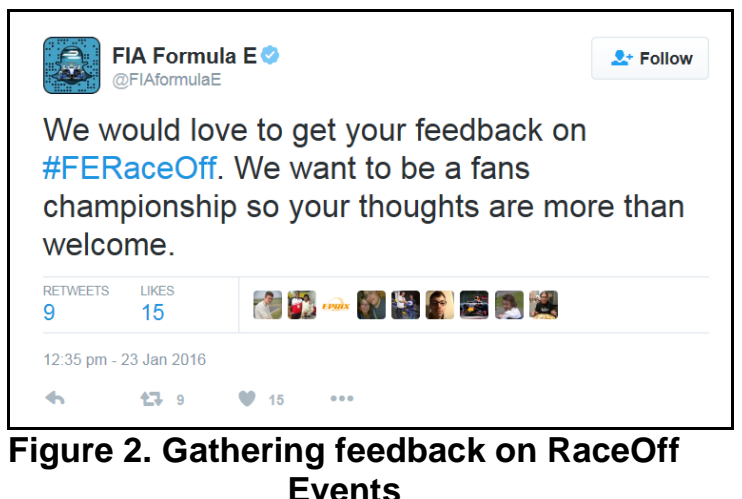

FE built on this gaming experience in two ways. First, the "eRace" was launched - a track-side event to fill in the time slot between qualifying and the race. In particular, the fan who set the fastest time on the race simulators during the day had a chance to compete 
with professional Formula E drivers during the eRace. Also, the events followed the rhythm of the ePrixs, resulting in an ebb and flow of interest. The most unique aspect of it seemed to be the emotional connection made possible by the move from solitary to relational participation, as one fan notes: "It's great that I can go from racing in my bedroom to racing against a Formula E driver who won last week."

Second, FE announced a stage for the best gamers worldwide to compete with each other. In particular, the "RaceOff Pro Series" involved fastest-lap time competitions among gamers before each ePrix. The fastest drivers were invited to participate in a virtual race the day before the ePrix, and the winners of these virtual races were invited to an all-expenses paid trip to the grand finale, held in a custom-built eSports arena in London where the final ePrix also took place. The downside of this initiative, as social interactions indicated, was that it required users to have the Xbox console, which was only one of the three main video game console makers, along with Sony PlayStation and Nintendo Wii. The market is equally divided among the three, and this exclusiveness was not in line with the expectations of the gaming community. In addition, gaming is increasingly moving to mobile and virtual reality, which might provide an opportunity for FE to be a trailblazer in terms of these technologies as well.

Moreover, through eSports, FE was exploring the limitations of simulated racing. Its 2017 plan included setting up a virtual-only race among its real drivers, and FE management indicated such races might provide points for the championship in the future. They also have been contemplating a blending of the two worlds and having virtual and real-world drivers compete in the same race.

Another sports category in which FE was pushing the boundaries is driverless car races. In Season 3, kicked off in Fall 2016, FE included plans to launch Roborace, as a support series for FE. FE management commented: "Others could have announced a driverless car championship, but they probably didn't dare to. For Formula E, this kind of bold initiative makes sure we explore possible directions for the future. In particular, this [move] provides tremendous opportunity for excitement as there are no concerns about driver safety. Moreover, there could be competitions of [hu]man-vs.-machine."

In the Roborace series, ten teams would compete, each using the same car. For the design of the car (see Figure 3), automotive futurist Daniel Simon was engaged. Simon, known for his vehicle designs in blockbuster movies, such as Tron: Legacy and Captain America, commented that "the Roborace is as much about competition as it is entertainment. Therefore, and quite unusual in today's racing world, beauty was very high on our agenda and we worked hard to merge the best performance with stunning styling."

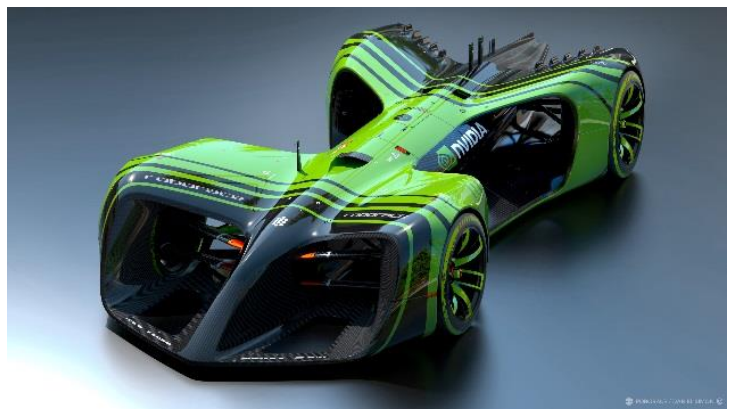

Figure 3. Robocar

Denis Sverdlov, CEO of Roborace, added: "Roborace will provide its viewers with a fascinating spectacle as the world's best minds will compete with each other to create the fastest and most efficient race cars around. Now, the whole racing team will be at the center of attention throughout the competition, whereas previously attention could only focus on drivers." Three types of teams were to be competing: traditional car manufacturers, technology firms (e.g., Google and Apple), and crowd-sourced teams. In particular, to explore opportunities for engaging fans, the public-especially teams of coders from tech startups and universities-will be able to submit algorithms, which will then race against the other teams.

Also, given the tension associated with car crashes - a spectacle for fans, yet potentially creating distrust in the technology-Roborace is expected to simultaneously explore two formats of Roborace competition. Sverdlov explains: "One will be about the safety and the other one will be called 'fight mode,' where the cars can behave quite aggressively. We really want to involve our technology partners to work out the right balance between safety and the show."

The announcement of the new sports category already had caused a lot of stir within the community, as the quote from this skeptical fan illustrates" : $I f$ every car is plugging away lap after neatly programmed lap, where will the action be? You can't intimidate machinery. You can't get up in the mirrors of a robot and make them sweat by hanging right off their bumper until they either move over or screw up."

\section{Discussion and conclusion}

In this paper, we identified gaps at the intersection of the literatures on ecosystems, radical innovation, and

\footnotetext{
2 http://blackflag.jalopnik.com/who-do-you-root-for-when-no-onesdriving-an-autonomous-1768409635
} 
entrepreneurial opportunity formation. To address the literature's missing perspective in early-stage entrepreneurial ecosystems, the research question was: "How does an entrepreneurial firm grow an emerging ecosystem for radical innovation?" We have analyzed this question in the context of a new venture, Formula $\mathrm{E}$ in the sports and entertainment industry, that is reinventing the motorsports world with digital technologies.

Our triangulation of the observed patterns from FE's initiatives and the literature advanced a concept of entrepreneurial probing. We define entrepreneurial probing to follow the key elements of probing in the human interaction design literature. Probing constitutes of deliberate provocation and open-ended dialog and conversation about need-solution pairs. Entrepreneurial probing shares the goal of cultural probes that focus on uncovering needs of target groups that the designer is unfamiliar with. Entrepreneurial probing also includes technological probing that makes users aware of emerging technological solutions, trends and developments and gathers social information regarding their acceptance [2]. As entrepreneurial probing addresses need-solution pairs, the core notion of opportunity formation is maintained in the engagement strategy.

Just as probes in general, entrepreneurial probes do not aim to seek general or average characteristics, to validate expectations, or to "solve" a particular problem, but rather to discover what previously was invisible or hidden. They aim to explore the surprises, unexpected uses, and unintended consequences and tensions produced from people's real, lived-with experiences. Hence, probes do not narrow the scope of innovation or its meaning but rather expand it.

Entrepreneurial probing aims to overcome takenfor-granted assumptions and to open up new possibilities in an emerging ecosystem. FE challenged the notions of how motorsports are experienced, performed, and defined. What we observed at FE is that, through its initiatives, it did not try to converge and validate design requirements or understand or proclaim commonalities of possible fan and customer communities; rather, it sought to provoke new interaction, reflection, and debate and thereby to increase uncertainty. In particular, FE discovered huge variations in reactions on its initiatives. For instance, eSports and Roborace invigorated tensions among fans about what the essence of motorsports was, and the immersive fan-centric experiences revealed what fans were looking for when attending a race.

Entrepreneurial probing engendered open-ended dialog and discussion that linked to social trends and diverse user communities, as well as fueled tensions among and between communities. Platforms for probing at FE included Facebook groups, updates and comments, Twitter posts and polls, Web Forum interactions, Blog posts, and wikis. Through probing, social trends were identified at FE, such as the specifics of the FanBoost mechanism and its potential manipulation. Probing provided inspirations about unfolding developments that lead to entry of new actors into the ecosystem. For instance, the introduction of Roborace brought established universities into the ecosystem.

Besides the deliberate and emergent elements, we assert that entrepreneurial probing addresses both needs and solutions at the same time. Entrepreneurial probing encourages ambiguity and involves pushing boundaries of innovation landscapes so that diverse actors can then pursue heterogeneous need-solution pairs that fit with their own unique innovation trajectories. Entrepreneurial probing can expand a landscape for diverse user communities including leadusers [31]. A case in point is FE's endeavors in eSports, in which it motivates professional gamers to compete against real-life racers.

While probing can be thought of as a form of exploratory learning, it lacks some of the aspects often associated with exploration [32]-[35]. The literature argues for highly selective exploration by a new venture with limited resources. Exploration should be tightly focused on an identified problem. However, we see a broad range of initiatives at FE, many of which have little in common. The exploration literature also argues that to gain value from exploration, there needs to be integration of new knowledge. However, we saw little evidence of integration of knowledge across initiatives at FE. In addition, probing assumes engagement including co-creation that is not necessarily present in exploratory learning. Also, entrepreneurial probing does not involve experimentation, which comprises developing a hypothesis and systematic evaluation [36]. Instead, entrepreneurial probing is about "feeling around," or poking for interest or attraction in previously unfamiliar territories.

In this paper, we have advanced entrepreneurial probing as a concept that we speculate might generalize to other early-stage entrepreneurial ecosystems. We hope we have identified a potential research area, probing at emergent entrepreneurial ecosystems, that can trigger subsequent theorizing and systematic and rigorous empirical inquiries.

\section{References}

[1] T. Ogilvie, "How to Thrive in the Era of Collaborative Services Entrepreneurship," Research Technology Management, vol. 58, no. 5, pp. 24-33, 2015. 
[2] E. Autio, L. Dahlander, and L. Frederiksen, "Information Exposure, Opportunity Evaluation, and Entrepreneurial Action: An Investigation of an Online User Community," Academy of Management Journal, vol. 56, no. 5, pp. 1348-1371, 2013.

[3] R. F. Lusch and S. Nambisan, "Service Innovation: A Service-Dominant-Logic Perspective," MIS Quarterly, vol. 39, no. 1, pp. 155-175, 2015.

[4] S. Faraj, S. L. Jarvenpaa, and A. Majchrzak, "Knowledge Collaboration in Online Communities," Organization Science, vol. 22, no. 5, pp. 1224-1239, 2011.

[5] J. F. Moore, "Predators and Prey: a New Ecology of Competition," Harvard Business Review, vol. 71, no. 3, pp. 75-86, 1993.

[6] S. Nambisan and R. A. Baron, "Entrepreneurship in Innovation Ecosystems: Entrepreneurs' Self-Regulatory Processes and Their Implications for New Venture Success," Entrepreneurship Theory and Practice, vol. 37, no. 5, pp. 1071-1097, 2013.

[7] S. Nambisan, "Digital Entrepreneurship: Towards a Digital Technology Perspective of Entrepreneurship," Entrepreneurship Theory and Practice, vol. Forthcomin, 2016.

[8] L. D. W. Thomas, E. Autio, and D. M. Gann, "Architectural Leverage: Putting Platforms in Context," Academy of Management Perspectives, vol. 28, no. 2, pp. 198-219, May 2014.

[9] A. Gawer and M. A. Cusumano, "Industry Platforms and Ecosystem Innovation," Journal of Product Innovation Management, vol. 31, no. 3, pp. 417-433, 2014.

[10] C. M. L. Leong, S.-L. Pan, S. Newell, and L. Cui, "The Emergence of Self-Organizing E-Commerce Ecosystems in Remote Villages of China: A Tale of Digital Empowerment for Rural Development," MIS Quarterly, vol. 40, no. 2, pp. 475-484, 2016.

[11] E. von Hippel and G. von Krogh, "CROSSROADSIdentifying Viable 'Need-Solution Pairs': Problem Solving Without Problem Formulation," Organization Science, vol. 27, no. 1, pp. 207-221, 2016.

[12] S. A. Alvarez, J. B. Barney, and P. Anderson, "Forming and Exploiting Opportunities: The Implications of Discovery and Creation Processes for Entrepreneurial and Organizational Research," Organization Science, vol. 24, no. 1, pp. 301-317, 2013.

[13] O. A. El Sawy, A. Malhotra, Y. Park, and P. A. Pavlou, "Seeking the Configurations of Digital Ecodynamics: It Takes Three to Tango," Information Systems Research, vol. 21, no. 4, pp. 835-848, 2010.

[14] Z. McDougall and S. Fels, "Cultural Probes in the Design of Communication," in ACM sigDOC'10 Conference on Design of Communication, 2010, pp. 57-64.

[15] R. Adner, "Match Your Innovation Strategy to Your Innovation Ecosystem," Harvard Business Review, vol. 84, no. April, pp. 2-11, 2006.

[16] S. A. Zahra and S. Nambisan, "Entrepreneurship and Strategic Thinking in Business Ecosystems," Business Horizons, vol. 55, no. 3, pp. 219-229, 2012.

[17] K. Lyytinen, Y. Yoo, and R. J. Boland, "Digital Product Innovation within Four Classes of Innovation Networks," Information Systems Journal, vol. 26, no. 1, pp. 47-75, 2016.

[18] R. J. Boland, K. Lyytinen, and Y. Yoo, "Wakes of
Innovation in Project Networks: The Case of Digital 3-D Representations in Architecture, Engineering, and Construction," Organization Science, vol. 18, no. 4, pp. 631647, 2007.

[19] A. Majchrzak, D. Logan, R. McCurdy, and M. Kirchmer, "Four Keys to Managing Emergence," MIT Sloan Management Review, vol. 47, no. 2, pp. 14-18, 2006.

[20] H. H. Stevenson, "Why Entrepreneurship Has Won," Coleman White Paper, pp. 1-8, 2000.

[21] H. H. Stevenson and J. C. Jarillo, "A Paradigm of Entrepreneurship: Entrepreneurial Management," Strategic Management Journal, vol. 11, no. 4, pp. 17-27, 1990.

[22] J. S. Mcmullen and D. Dimov, "Time and the Entrepreneurial Journey: The Problems and Promise of Studying Entrepreneurship as a Process," Journal of Management Studies, vol. 50, no. 8, pp. 1481-1512, 2013.

[23] S. Nambisan and S. A. Zahra, "The Role of DemandSide Narratives in Opportunity Formation and Enactment," Journal of Business Venturing Insights, vol. 5, pp. 70-75, 2016.

[24] K. Boehner, J. Vertesi, P. Sengers, and P. Dourish, "How HCI Interprets the Probes," SIGCHI Conference on Human Factors in Computing Systems (CHI'07), pp. 10771086, 2007.

[25] W. Gaver, A. Dunne, and E. Pacenti, "Cultural Probes," Interactions, vol. 6, no. 1, pp. 21-29, 1999.

[26] W. Gaver, A. Boucher, S. Pennington, and B. Walker, "Cultural Probes and the Value of Uncertainty," Interactions, vol. 11, no. 5, pp. 53-56, 2004.

[27] E. Ries, The Lean Startup: How Today's Entrepreneurs Use Continuous Innovation to Create Radically Successful Businesses. Crown Business, 2011.

[28] W. Gaver and A. Dunne, "Projected Realities: Conceptual Design for Cultural Effect," Proceedings of the SIGCHI Conference, pp. 600-607, 1999.

[29] K. M. Eisenhardt, "Building Theories from Case Study Research," The Academy of Management Review, vol. 14, no. 4, pp. 532-550, 1989.

[30] R. K. Yin, Case Study Research: Design and Methods, 5th ed. SAGE Publications, 2014.

[31] S. Thomke and E. von Hippel, "Customers as Innovators: A New Way to Create Value," Harvard Business Review, vol. 80, no. 4, pp. 74-81, 2002.

[32] J. G. March, "Exploration and Exploitation in Organizational Learning," Organization Science, vol. 2, no. 1, p. 71, 1991.

[33] A. Marino, P. Aversa, L. F. Mesquita, and J. Anand, "Driving Performance Via Exploration In Changing Environments: Evidence From Formula One Racing," Organization Science, vol. 26, no. 4, pp. 1079-1100, 2015.

[34] D. Lavie, U. Stettner, and M. L. Tushman, "Exploration and Exploitation Within and Across Organizations," The Academy of Management Annals, vol. 4, no. 1, pp. 109-155, 2010.

[35] H. E. Posen and D. A. Levinthal, "Chasing a Moving Target: Exploitation and Exploration in Dynamic Environments," Management Science, vol. 58, no. 3, pp. 587-601, 2012.

[36] S. Thomke, "Enlightened Experimentation: The New Imperative for Innovation," Harvard Business Review, vol. 79, no. 2, 2001. 